\title{
Model Pengukuran Faktor dan Indikator yang Berperan Terhadap Produktivitas Pendidikan Vokasi
}

\author{
Mulianti $^{1^{*}}$ \\ ${ }^{1}$ Jurusan Teknik Mesin, Fakultas Teknik, Universitas Negeri Padang \\ *Corresponding author, e-mail: muliantihendrik@gmail.com
}

\begin{abstract}
Abstrak- Penelitian ini bertujuan untuk: (1) mengidentifikasi validitas dan reliabilitas indikator dari faktor-faktor yang berperan pada produktivitas pendidikan vokasi; (2) membuat model pengukuran faktor dan indikator yang berperan terhadap produktivitas pendidikan vokasi. Populasi penelitian adalah lulusan D3 pendidikan vokasi dari Fakultas Teknik Universitas Negeri Padang dan Politeknik Negeri Padang. Teknik sampling menggunakan simple random sampling, dengan sumber data penelitian meliputi 398 responden lulusan lulusan D3 pendidikan vokasi dari Fakultas Teknik Universitas Negeri Padang dan Politeknik Negeri Padang. Analisis data dengan Lisrel 8.80 berupa uji normalitas dan uji multikolonieritas dilanjutkan estimasi asymptotic covariance matrix dengan analisis confirmatory factor analysis. Hasil penelitian mengungkap sebagai berikut: (1) terdapat 23 indikator yang valid dan reliabel dalam merefleksikan enam variabel yaitu kepemimpinan pengelola, dengan indikator idealized influence, inspirational motivation, intelectual stimulation, individualized consideration; suasana akademik dengan indikator lingkungan fisik, lingkungan belajar dan lingkungan akademik; kompetensi dosen dengan indikator kompetensi pedagogik, kompetensi profesional kompetensi kepribadian dan kompetensi sosial; sistem pembelajaran, dengan indikator learner-focused, worker-focused, attribut-oriented; proses pembelajaan dengan indikator mutu data informasi, mutu pembelajaran, mutu kurikulum, mutu sumber daya; dan produktivitas pendidikan vokasi, dengan indikator mutu lulusan, mutu manajemen, efisiensi internal, efisiensi eksternal, dan penghasilan.
\end{abstract}

Kata kunci: Produktivitas, Kepemimpinan Pengelola, Suasana Akademik, Kompetensi dosen, Sistem pembelajaran

Abstract - This study aimed to: (1) identify the validity and reliability of indicators of factors that contribute to the productivity of vocational education; (2) create measurement model of contributed factors and indicators to the productivity of vocational education. The research population is Diploma III graduates of vocational education from the Engineering Faculty of UniversitasNegeri Padang and Padang State Polytechnic. Sampling technique used was simple random sampling, in which the respondents were 395 graduates from Diploma III of vocational education from Faculty of Engineering of Padang State University and PadangState Polytechnic. Data were analyzed with LISREL 8.80 in the form of normality test and multicollinearity test and were continued with asymptotic covariance matrix estimation and confirmatory factor analysis. The results of the research showed that there were 23 valid and reliable indicators in reflecting the six variables; they were managerial leadership, with idealized influence, inspirational motivation, intellectual stimulation, individualized consideration; academic atmosphere with physical environmental indicators, learning environment, and academic environment; lecturer competence with pedagogic competency indicator, professional competence of personality competence and social competence; learning system, with learner-focused, workerfocused, attribute-oriented indicators; the process of learning with quality information data indicator, learning quality, curriculum quality, resource quality; and productivity of vocational education, with indicators of graduate quality, management quality, internal efficiency, external efficiency, and income.

Keywords: Productivity, Managers' Leadership, Academic Atmosphere, Lecturers' Competencies,Teaching Process.

This is an open access article distributed under the Creative Commons 4.0 Attribution License, which permits unrestricted use, distribution, and reproduction in any medium, provided the original work is properly cited. @2018 by Author and Universitas Negeri Padang 


\section{Pendahuluan}

Kajian ini berangkat dari masalah produktivitas pendidikan vokasi yang perlu ditingkatkan. Hal tersebut terlihat dari angka produktivitas yang relatif masih rendah, belum lagi masalah pengangguran, relevansi, lulus tepat waktu, kepercayaan publik, mutu lulusan dan lain-lain. Mencermati masalah produktivitas pendidikan vokasi tersebut, perlu diketahui akar permasalahannya berupa faktor beserta indikator apa saja yang berperan terhadap produktivitas pendidikan vokasi. Penelitian yang pernah dilakukan sebelumnya adalah tentang produktivitas sekolah di SMK [21], namun masih bersifat parsial dan belum pernah dilakukan penelitian serupa di pendidikan tinggi vokasi.

Penelitian ini bertujuan untuk mengungkap model pengukuran indikator-indikator dari faktor produktivitas pendidikan vokasi dan variabel yang mempengaruhi produktivitas pendidikan vokasi secara komprehensif. Artinya model yang dibuat dengan merespesifikasikan sebuah model hybrid sebagai model confirmatory factor analysis (CFA), sehingga model yang dihasilkan merupakan model rangkaian keseluruhan indikator yang merefleksikan masing-masing variabel dalam kaitannya dengan produktivitas pendidikan. Secara rinci tujuan penelitian ini adalah :

a.Mengkaji model pengukuran produktivitas Pendidikan vokasi, mencakup variabel beserta indikator yang berperan terhadap produktivitas Pendidikan vokasi.

b.Mengidentifikasi validitas dan reliabilitas faktorfaktor beserta indikator-indikator yang berperan terhadap produktivitas Pendidikan vokasi.

\section{Studi PUSTaka}

Produktivitas dalam dunia pendidikan berkaitan dengan keseluruhan proses perencanaan, penataan dan pendayagunaan sumber daya untuk merealisasikan tujuan pendidikan secara efektif dan efisien. Berdasarkan [1] menyatakan bahwa produktivitas pendidikan mencakup tiga fungsi berikut: (1) the Administrative Production Function (PFI), yaitu fungsi manajerial yang berkaitan dengan berbagai pelayanan untuk kebutuhan peserta didik dan staf pengajar. Masukan diidentifikasi diantaranya adalah adanya perlengkapan pembelajaran, ruangan, buku dan kualifikasi pendidik yang memungkinkan tercapainya pelaksanaan pendidikan secara efektif; (2) the Psichologist's Production Function (PPF), yaitu fungsi behavioural yang keluarannya merujuk pada fungsi pelayanan yang dapat mengubah prilaku peserta didik dalam kemampuan intelektual, kemampuan sosial, kemampuan emosional dan kemampuan spiritual; (3) the Economic Production Function (EPF), yaitu fungsi ekonomi yang keluarannya diidentifikasi sebagai lulusan yang memiliki kompetensi tinggi sehingga ketika bekerja dapat memperoleh penghasilan tinggi melebihi biaya pendidikan yang telah dikeluarkan. The Joint Commission on Accountability Reporting (JCAR), dalam pengembangan akuntabilitas dan produktivitas pendidikan tinggi memfokuskan diri pada: (1) tingkat perolehan pekerjaan secara purna waktu sesudah penyelesaian program atau studi di perguruan tinggi, (2) tingkat kelulusan, tingkat kegagalan dan perpindahan mahasiswa, (3) biaya beban mahasiswa (dibedakan antara yang dibayar oleh mahasiswa dan yang sesungguhnya dkeluarkan oleh lembaga pendidikan), (4) aktivitas dosen [13].

Beberapa unsur yang menentukan produktivitas diantaranya adalah kepemimpinan pengelola, pendidik/guru, sarana prasarana, siswa dan unsur penunjang lainnya. Khusus bagi pendidik/staf pengajar memegang peranan penting di dalam produktivitas lembaga pendidikan, tergantung dari berbagai hal yang saling berhubungan diantaranya adalah dengan sarana prasarana, proses, pemimpin, siswa, aturan serta unsur-unsur lainnya. Berdasarkan hasil penelitiannya, ternyata terdapat: (1) pengaruh langsung dan pengaruh tidak langsung kepemimpinan kepala sekolah terhadap produktivitas sekolah; (2) terdapat pengaruh langsung dan pengaruh tidak langsung budaya akademik terhadap produktivitas sekolah; (3) terdapat pengaruh langsung kompetensi guru terhadap produktivitas sekolah [17].

Pendidikan vokasi harus berorientasi pasar dan bisnis, sehingga budaya perusahaan dapat diintegrasikan dengan ide-ide dalam menjalankan pendidikan. Berdasarkan pada integrasi budaya akademik dan budaya enterprise, dosen harus mengikuti aspek-aspek pengelolaan kualitas humanistic mahasiswa, mencakup pembekalan pengetahuan profesional, keterampilan kerja serta kerja sama tim dan sebagainya, guna pemenuhan persyaratan perusahaan/tempat kerja [5].

Definisikan iklim sekolah sebagai: "an ordinary environtment in which the school family feels valued and able to pursue the school's mission free from concerns about disruptions and safety". Empat aspek dalam iklim sekolah tersebut yaitu : (1) lingkungan fisik yang mendukung pendidikan dan pengajaran; (2) lingkungan sosial yang 
mendukung komunikasi dan interaksi; (3) lingkungan afektif yang mendukung rasa memiliki; (4) lingkungan akademik yang mendukung pembelajaran [24]

Dosen merupakan faktor utama dalam penciptaan suasana pembelajaran pada proses pembelajaran. Rumusan 32nd Annual Kappan Gallup Poll yang menemukan harapan masyarakat bahwa: "the best strategy for improving school achievement to be qualified and competent teachers in every classroom", sebagaimana [24] merumuskan: competency standards have uses including a means of governance; legitimating education; defining the purposes of education; teacher appraisal; improvement in teaching; a curriculum for teacher education; the improvement in the standard and quality of student learning; workplace reform; increasing efficiencies; and the promotion of teaching as a profession. It has also been suggested that they have uses in implementing differential pay scale for teachers.

Lingkup pendidikan vokasi, [20] merangkum berbagai skill yang dibutuhkan tenaga pendidik yang meliputi: (a) memiliki pengalaman dan praktek pembelajaran; (b) pengetahuan pengelolaan kelas, isu multikultural, teori pembelajaran, metode penilaian mahasiswa, aplikasi teori dalam praktek, kurikulum dan pembelajaran dan integrasi teknologi dalam pembelajaran; (c) kemampuan bekerja kolaboratif dengan rekan sejawat, orang tua dan masyarakat.

Karakteristik dosen yang profesional dikemukakan oleh [20] dalam suatu model teori karakteristik profesionalitas dosen. Terdapat tiga aspek model teoritis karakteristik profesional dosen, yaitu aspek pertama yaitu keterampilan (skills), aspek kedua yaitu perhatian kepada yang lain (concern of others), aspek ketiga adalah perhatian kepada diri sendiri (concern for self), berkaitan dengan pemberdayaan diri (empowernment), pengembangan diri (self-development) dan penggajian (remuneration). Penelitian [21] menganalisis kompetensi dosen terhadap kinera dosen, yang menjadi populasi adalah seluruh mahasiswa UIN Sultan Syarif Kasim Riau yang berjumlah 13.698 orang dan yang menjadi sampel sebanyak 388 orang dengan menggunakan metode random sampling. Pengaruh kompetensi pedagogik, kompetensi profesional, kompetensi kepribadian dan kompetensi sosial secara simultan (bersama-sama) sebesar 0,653 atau 65,3 \% berpengaruh terhadap kompetensi dosen.

Karakteristik kepemimpinan transformasional sangat sesuai jika diterapkan pada bidang pendidikan, dijelaskan [22], sebagai berikut : (1) idealized influence/kharisma, mensinkronkan antara nilai-nilai yang diungkapkan lewat kata-kata dengan nilai-nilai yang diwujudkan dalam tindakan, menanamkan rasa bangga, mendapatkan respek dan kepercayaan (trust); (2) inspirational motivation, memotivasi bawahan, mengkomunikasikan ekspektasi yang tinggi, menggunakan simbol untuk memfokuskan upaya, mengekspresikan tujuan dengan cara-cara yang sederhana. ; (3) simulasi intelektual (intelectual stimulation), menciptakan iklim yang kondusif bagi berkembangnya inovasi dan kreativitas, menghargai ide-ide bawahan (promote intelegence), mengembangkan rasionalitas dan melakukan pemecahan masalah secara cermat.; (4) pertimbangan individual (individualized consideration), memberikan perhatian pada pribadi, menghargai perbedaan secara individu, memberikan nasihat dan pengarahan. Sejumlah 284 responden dosen dan staf administrasi dari beberapa pendidikan vokasional politeknik di Ghana, dengan menggunakan instrumen Multifactor Leadership Questionnaere (MLQ), diperoleh kesimpulan bahwa praktik kepemimpinan transformasional berdampak signifikan terhadap lingkup kerja pendidikan vokasi [3]. Penelitian yang dilakukan [14] dengan responden 290 dosen politeknik di Kedah, menyimpulkan terdapat hubungan yang signifikan antara gaya kepemimpinan pengelola dengan budaya kerja.

Merujuk dari ulasan [20] dan [3] dengan menyesuaikan kondisi, potensi serta ruang lingkup pendidikan vokasi yang membutuhkan kepemimpinan yang piawai membangun kerja sama dan kemitraan dengan dunia usaha/industri dan pihak berkepentingan, melakukan terobosanterobosan dalam ide-ide/program/pemecahan masalah, pertimbangan individu terhadap anggota dalam memotivasi pencapaian visi dan misi, berorientasi kerja, maka pada penelitian ini kepemimpinan pengelola menggunakan indikator dari kepemimpinan transformasional, sebagai berikut: (1) idealized Influence/Kharisma; (2) inspirational motivation; (3) simulasi intelektual (intelectual stimulation); dan (4) pertimbangan individual (individualized consideration).

\section{METODE}

Penelitian melibatkan 390 responden lulusan D3 Fakultas Teknik Universitas Negeri Padang dan Politeknik Negeri Padang.

Screening data 
Sebelum melakukan analisis confirmatory factor analysis (CFA), maka dilakukan screening data untuk memberikan gambaran mengenai deskriptif data untuk memastikan terpenuhinya asumsi SEM yaitu normality dan multicollinearity. Analisis Model Pengukuran/Confirmatory Factor Analysis (CFA).

Model pengukuran pada penelitian ini memodelkan hubungan yang dihipotesiskan bersifat reflektif antara variabel laten yaitu kepemimpinan pengelola (Manlead), suasana akademik (Atmosac), kompetensi dosen (Lectcomp), sistem pembelajaran (Teachsym), proses pembelajaran (Process) dan produktivitas pendidikan vokasi (Product) dengan variabel teramati yang berjumlah 23 variabel, berdasarkan substansi dan studi literatur. Kemudian dilakukan analisis model pengukuran/Confirmatory Factor Analysis (CFA), dimana model pengukuran akan mengkonfirmasi apakah variabel teramati tersebut memang merefleksikan variabel laten. Tahap analisis meliputi: spesifikasi model; pengumpulan data; pembuatan program simplis; menjalankan program dengan LISREL 8.8; dan analisis output. Analisis terhadap output, secara umum adalah: pemeriksaan adanya offending estimate(meliputi negative error variance/Heywood cases); standardized loading factor 1,0; serta standard error yang besar. Jika ada maka dilakukan respesifikasi model sesuai kebutuhan.

Uji kecocokan keseluruhan model; dilakukan pemeriksaan terhadap nilai chi-square, p-value, RMSEA, Standardized RMR, GFI, AGFI, NFI, NNFI, CFI dan lain-lain yang ditampilkan pada Goodness of Fit Statistics.

Analisis reliabilitas model pengukuran; dilakukan dengan menghitung nilai construct reliability (CR) dan variant extracted (VE) dari nilai standardized loading factor dan error variance dengan rumus berikut [11]:

$$
\begin{aligned}
& \mathrm{CR}=\frac{\left(\sum \text { std.loading }\right)^{2}}{\left(\sum \text { std.loading }\right)^{2}+\sum \mathrm{e}_{\mathrm{j}}} \\
& \mathrm{VE}=\frac{\sum \text { std. loading }{ }^{2}}{\sum \text { std. loading }{ }^{2}+\sum \mathrm{e}_{\mathrm{j}}}
\end{aligned}
$$

dengan:

$\sum \mathrm{e}_{\mathrm{j}}=$ measurement error untuk setiapindikator.

Sebuah konstruk mempunyai reliability yang baik jika nilai construct reliability $(\mathrm{CR}) \geq 0,70$ dan nilai variance extraxcted (VE) $\geq 0,50$ [13].

\section{HASIL DAN PEMBAHASAN}

\section{A. Confirmatory Factor Analysis (CFA).}

Penetapan variabel teramati yang berjumlah 23 variabel telah dilakukan berdasarkan substansi studi literatur. Selanjutnya melalui model pengukuran mengkonfirmasi apakah variabel teramati tersebut memang merupakan ukuran/refleksi dari sebuah variabel laten. Maka untuk tujuan tersebut dilakukan Confimatory Factor Analysis (CFA). Analisis model terhadap outputnya dilakukan melalui beberapa tahapan:

Analisis awal terhadap hasil estimasi.

Menganalisis adanya offending estimate, yaitu adanya negative error variance (Heywood cases) dan standardized loading factor 1,0 , serta nilai standard error yang sangat besar. Hasil pengamatan yang dilakukan tidak terdapat adanya negative error variance maupun standardized loading factor yang 1,0. Nilai error variance tersebut diamati berdasarkan Output, dan tidak ditemukan error variance yang bernilai negatif.

\section{Analisis validitas model pengukuran}

Analisis validitas model pengukuran dilakukan melalui: a). pemeriksaan terhadap t-value dari loading factor dari variabel teramati. Suatu variabel dikatakan mempunyai validitas yang baik terhadap konstruk atau variabel laten, jika t-value dari muatan faktornya (loading factor) lebih besar dari nilai kritis (atau $\geq 1,96$ untuk taraf signifikansi 5\%). [23] serta [8].

Dari pengamatan Gambar 2, ternyata dari semua variabel teramati, tidak terdapat t-value yang lebih kecil dari 1,96. Nilai terkecil adalah 7.374 pada Y19; b). melakukan pemeriksaan Standardized loading factor $(\lambda)$ dari variabel teramati dalam model. Apakah nilainya $\geq 0,70$ [23] atau $\geq 0,50$ [16], dimana nilai standardized loading factor dapat dilihat pada diagram lintasan (standardized solution) Gambar 1 atau pada printed output bagian completely standardized solution. Dari pengamatan analisis validitas tersebut ternyata standardized loading factor $(\lambda)$ dari variabel teramati semuanya $\geq$ nilai cut off yang ditetapkan, yaitu $\geq 0,50$. Dalam kaitannya dengan validitas model pengukuran, maka variabel teramati yang mempunyai $\mathrm{t}$-value 1,96 atau standardized loading factor lebih kecil dari nilai cut off yang dipilih, yaitu $\leq 0,70$ atau $\leq 0,50$ dikeluarkan ( atau tidak disertakan dalam model), atau dengan kata lain variabel teramati yang bersangkutan dihapus dari model. 


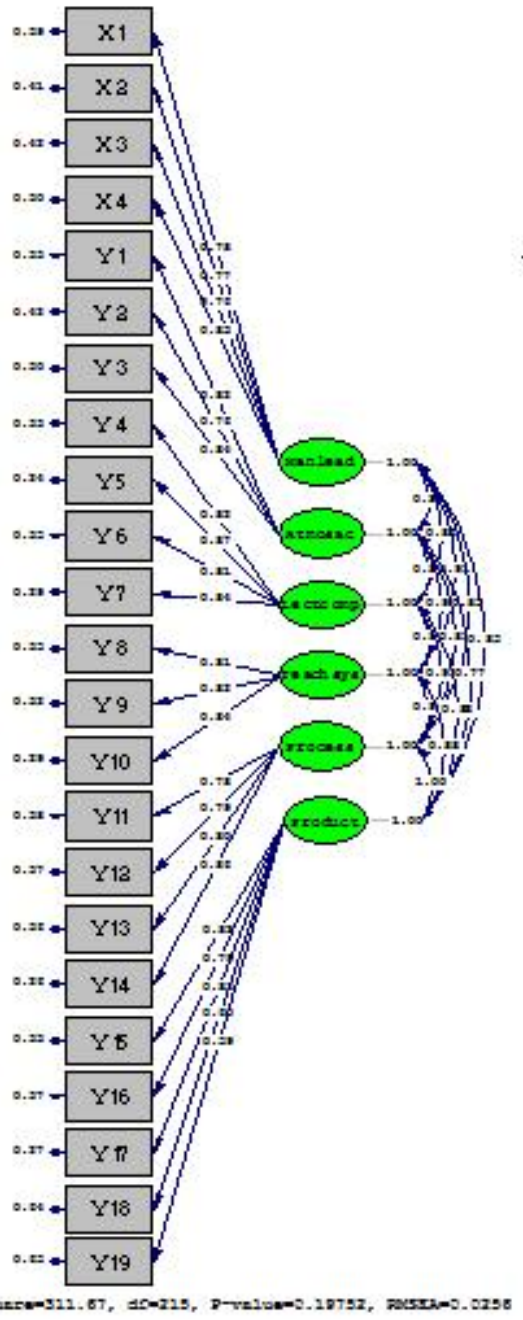

Gambar 1. Diagram Lintasan Model Pengukuran Faktor Determinan Produktivitas Pendidikan Vokasi (standardized solution)

Dari pengamatan analisis validitas tersebut telah dinyatakan bahwa semuanya $\geq$ nilai cut off yang ditetapkan. Dari kedua analisis validitas terhadap output, diperopeh kesimpulan awal bahwa hasil estimasi muatanfaktor dari model adalah valid.

\section{Analisis kecocokan keseluruhan model.}

Dari analisis Goodness of Statistic, diamati bahwa Indeks kecocokan, Normed Fit Index $(\mathrm{NFI})=0,974$, Non-Normed Fit Index $(\mathrm{NNFI})=$ 0,990 , Parsimony Normed Fit Index (PNFI) = 0,928, Comparative Fit Index $(\mathrm{CFI})=0,99$, Incremental Fit Index (IFI) $=0,992$, Relative Fit Index $(\mathrm{RFI})=0,969$ (semuanya $\geq 0,90$, kecocokan model baik [4]. RMSEA 0,0256 $(\leq 0,05)$, ini menandakan model fit yang baik [4]. Demikian juga nilai Standardized Root Mean Square Residual (SRMR) 0,0269 ( $\leq 0,05)$, menandakan model good fit. Sedang Nilai Goodness of Fit Index (GFI) 0,839 adalah marginal fit $(0,8 \leq \mathrm{GFI} \leq 0,9$ adalah marginal Fit menurut Joreskog dan Sorbon, 1984), dan nilai Adjusted Goodness of Fit Index (AGFI) 0,793, ini juga dikategorikan marginal fit ( $0,8 \leq$ GFI $\leq 0,9$ adalah marginal fit [19]. ChiSquare 311,57 dan p-value 0,19702 adalah fit yang baik (p-value $\geq 0,05)$. Untuk nilai $\chi^{2} / \mathrm{df}$ $=311,57 / 215=1,44(<2$, memenuhi menurut [19]. Berarti model secara keseluruhan menunjukkan kecocokan yang baik. Hubungan antara variabel teramati/indikator dengan variabel laten dapat juga dinilai dari reliabilitas gabungan untuk tiap-tiap variabel laten melalui construct reliability dan variance extracted. Nilai dari standardized loading factors dan error variances (errors) diambil dari diagram lintasan pada printed output dari judul completely standardized solution dan subjudul LAMBDA-X (untuk nilai standardized loading factors) dan THETA DELTA (errors), (untuk error variance). Dari hasil perhitungan terlihat semua nilai Construct Reliability (CR) 0,70 dan Nilai Variance Extracted $\quad 0,50$.

\section{B. Analisis Reliabilitas Model.}

Untuk menganalisis reliabilitas indikator individual, dapat dilihat pada nilai squared multiple correlations $\left(\mathrm{R}^{2}\right)$ dari indikator melalui opsi LISREL OUTPUT. $\mathrm{R}^{2}$ menjelaskan seberapa besar proporsi varians indikator yang dijelaskan oleh variabel laten, sedang sisanya dijelaskan oleh measurement error. Dari output, dapat diketahui bahwa dari variabel laten kepemimpinan pengelolola, X4 (individual consideration) merupakan indikator yang paling reliabel, kemudian disusul oleh X1 (idealized influence), X2 (inspiration motivation) dan X3 (intelectual stimulation).

Variabel Suasana akademik, ternyata Y3 (lingkungan belajar) merupakan indikator yang paling reliabel, disusul Y1 (lingkungan fisik), kemudian Y2 (lingkungan akademik).

Dari variabel laten kompetensi dosen, Y4 (kompetensi pedagogik) adalah indikator yang paling reliabel, dilanjutkan Y7 (kompetensi sosial), Y6 (kompetensi kepribadian), dan Y5 (kompetensi proesional).

Untuk variabel laten sistem pembelajaran, Y9 (work-centered) merupakan indikator yang paling reliabel, disusul Y8 (lerner-centered), dan Y10 (focused-attribut). 


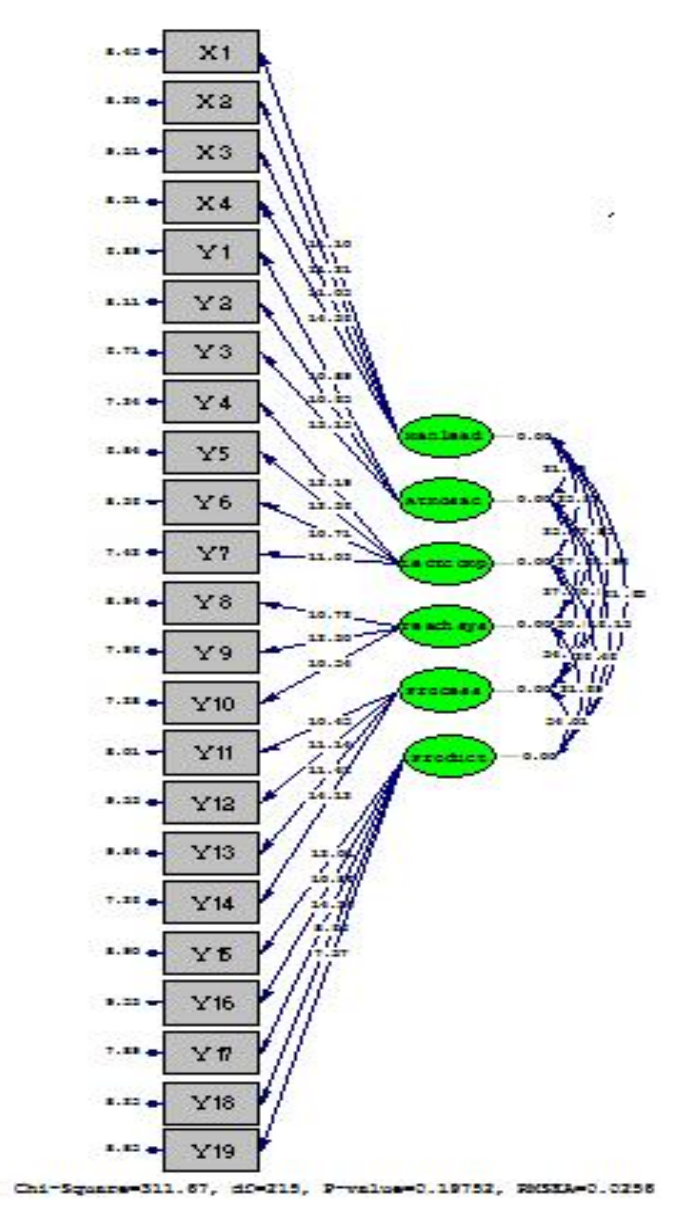

Gambar 2. Diagram Lintasan Model Pengukuran Faktor Determinan Produktivitas Pendidikan Vokasi (t-value)

Variabel laten proses pembelajaran, Y14 (mutu sumber daya); Y13 (mutu kurikulum); Y12 (mutu pemelajaran); Y11 (mutu data dan inormasi).

Sedang untuk variabel laten produktivitas pendidikan, Y17 (masa tunggu) merupakan indikator yang paling reliabel, disusul Y15 (mutu lulusan), Y16 (relevansi), Y18 (kepercayaan publik), and Y19 (penghasilan).

Hubungan antara variabel teramati/indikator dengan variabel laten dapat juga dinilai dari reliabilitas gabungan untuk tiap-tiap variabel laten melalui construct reliability dan variance extracted. Menurut [13] menyatakan bahwa sebuah konstruk mempunyai reliabilitas yang baik jika nilai construct reliability $\geq 0,70$ dan nilai variance extracted $\geq 0,50$. Demikian juga [2] menyatakan bahwa tingkat cut-off untuk dapat mengatakan reliabilitas gabungan (composite reliability) cukup bagus adalah 0,60 . Dari hasil olah data yang telah dilakukan ternyata seluruh indikator adalah reliabel, yaitu seluruh indikator memberikan ukuran yang reliabel untuk masing-masing variabel laten. Jadi dari pembahasan di atas dapat disimpulkan bahwa berdasarkan uji validitas maupun uji reliabilitas (baik ditinjau dari reliabilitas indikator individual maupun reliabilitas gabungan/composite reliability, melalui pengukuran construct reliability dan variance extracted), seluruh indikator adalah valid dan reliabeal, demikian juga seluruh variabel laten adalah reliabel.

Tabel 1. Hasil Perhitungan Construct Reliability (CR) dan Variance Extracted (VE).

Tabel 1. Hasil Uji Reliabilitas Variabel

\begin{tabular}{|c|c|c|c|}
\hline Variable & $C R(\nexists 0,70)$ & $V E(\searrow 0,50)$ & $\begin{array}{l}\text { Reliability } \\
\text { Conclusion }\end{array}$ \\
\hline Manlead & 0,866 & 0,619 & Good Reliability \\
\hline Atmosac & 0,848 & 0,650 & Good reliability \\
\hline Lectcom & 0,901 & 0,695 & Good Reliability \\
\hline Teachsys & 0,865 & 0,681 & Good Reliability \\
\hline Process & 0,885 & 0,657 & Good Reliability \\
\hline Product & 0,854 & 0,546 & Good Reliability \\
\hline
\end{tabular}

Penjelasan faktor atau variabel laten beserta indikator masing-masing adalah sebagai berikut:

Kepemimpinan pengelola.

Indikator dari variabel laten kepemimpinan pengelola yang diadaptasi dari Hemsworth, Muterera \& Baregheh [15]; dan [3], meliputi idealized influence, inspirational motivation, intelectual stimulation dan individual consideration, dengan questionnaire yang mereka namai Multifactor Leadership Questionnaire. The Multifactor Leadership Questionnaire yang telah digunakan di berbagai negara secara luas selama 20 tahun terakhir yang valid dan reliabel untuk berbagai budaya dan type organisasi, menurut [15], ternyata sesuai ketika diterapkan pada penelitian ini, dimana diperoleh fakta bahwa seluruh indikator kepemimpinan pengelola meliputi idealized influence, inspirational motivation, intelectual stimulation dan individual consideration memiliki validitas dan reliabilitas yang baik untuk mengukur konstruk kepemimpinan pengelola pendidikan vokasi.

Hasil perhitungan dan kesimpulan validitas dan reliabilitas untuk variabel kepemimpinan pengelola terlihat bahwa semua indikator adalah valid ( $\mathrm{t}$-value dari unstandardized yang lebih besar dari 1,96 dan standardized loading mempunyai $\geq$ $0,50)$ dan semua indikator adalah reliabel (nilai Construct Reliability (CR) $\geq 0,70$ dan Nilai Variance Extracted (VE) $\geq 0,50$ ), sesuai pendapat 
[13] sehingga dapat dinyatakan bahwa validitas dan reliabilitas variabel kepemimpinan pengelola baik, artinya semua indikator adalah valid dan konsisten dalam mengukur variabel kepemimpinan pengelola. Penjabaran dari indikator dari kepemimpinan pengelola tersebut item-item questionnaire dari penelitian ini adalah: (1) individualized consideration(pertimbangan individual), memberikan perhatian pada individu, menghargai perbedaan antara individu, memberikan nasihat dan pengarahan. Pemimpin memperlakukan secara berbeda tetapi seimbang dan adil terhadap jajarana guna memelihara kontak hubungan dan komunikasi yang terbuka; (2) idealized influence/kharisma, mensinkronkan antara nilai-nilai yang diungkapkan lewat kata-kata dengan nilai-nilai yang diwujudkan dalam tindakan, menanamkan rasa bangga, mendapatkan respek dan kepercayaan (trust). Pemimpin memiliki kharismatik dan mempunyai suatu kekuatan dan pengaruh. Pemimpin membangkitkan dan memberi semangat kepada jajaran civitas akademika dengan sebuah visi dan sense of mission yang mendorong untuk melakukan usaha yang lebih ekstra dalam mencapai tujuan; (3) inspirational motivation, memotivasi jajaran, mengkomunikasikan ekspektasi yang tinggi, menggunakan simbol untuk memfokuskan upaya, mengekspresikan tujuan. Prilaku pimpinan menstimulan antusiasme jajaran terhadap tugas dan dapat menumbuhkan kepercayaan jajaran terhadap kemampuan menyelesaikan tugas dalam mencapai tujuan; (4) intelectual stimulation, menciptakan iklim yang kondusif bagi berkembangnya inovasi dan kreativitas, menghargai ide-ide jajaran (promote intelegence), mengembangkan rasionalitas dan melakukan pemecahan masalah secara cermat. Pimpinan mendorong pengembangan rasionalitas dengan mempertimbangkan cara kreatif dan inovatif; individualized consideration (pertimbangan individual), memberikan perhatian pada individu, menghargai perbedaan antara individu, memberikan nasihat dan pengarahan. Pemimpin memperlakukan secara berbeda tetapi seimbang dan adil terhadap jajarana guna memelihara kontak hubungan dan komunikasi yang terbuka.

Suasana akademik

Variabel suasana akademik, yang memiliki tiga indikator yaitu lingkungan belajar; lingkungan fisik; dan lingkungan akademik [21] ternyata valid dan reliabel dalam mengukur variabel suasana akademik pada pendidikan vokasi. Ini dibuktikan dengan hasil uji validitas dan uji reliabilitas individu maupun gabungan (composite).
Lingkungan akademik yang diacu dari [24], dan dan disesuaikan dengan kewajiban perguruan tinggi sebagai penyelenggara pendidikan, penelitian dan pengabdian kepada masyarakat, Undang-undang No 12 Tahun 2012, dalam penelitian ini terbukti valid dan reliabel, sesuai dengan yang dituangkan dalam questionnaire pada penelitian ini, mencakup: adanya dukungan penuh terhadap akademik, namun semua intelegensi dan kompetensi didukung; pengharapan yang tinggi terhadap kesuksesan civitas akademika; dukungan terhadap program dan kegiatan interaksi akademik mahasiswa dan dosen; interaksi dosen dan mahasiswa melalui kegiatan penelitian dan pengabdian kepada masyarakat; interaksi dosen dan mahasiswa melalui kegiatan seminar, simposium dan lain-lain. Sesuai dengan yang direkomendasikan [23] lingkungan belajar sebagai indikator dari suasana akademik terbukti valid dan reliabel. Lingkungan belajar mengacu pada konteks sosial, psikologi dan pedagogi terhadap pelaksanaan pembelajaran. Mengacu pada questionnaire Lingkungan belajar meliputi: kekompakan peserta didik (student cohesiveness), dukungan tenaga pendidik, keterlibatan peserta didik dalam pembelajaran, kegiatan penyelidikan, orientasi tugas, kerjasama peserta didik dan kesetaraan.

\section{Kompetensi dosen}

Variabel laten kompetensi dosen, diacu dari Undang-undang Nomor 14 Tahun 2005 dan hasil penelitian [20], serta [18], dengan indikator Y4 (kompetensi pedagogik), Y5 (kompetensi profesional), Y6 (kompetensi kepribadian), dan Y7 (kompetensi sosial) ternyata dari hasil penelitian ini memiliki validitas dan reliabilitas yang baik, ini dibuktikan dengan hasil uji validitas dan uji reliabilitas yang telah dipaparkan sebelumnya, sehingga dapat disimpulkan bahwa keempat indikator tersebut valid dan reliabel dalam mengukur variabel kompetensi dosen vokasi. Indikator hasil penelitian dari variabel kompetensi dosen yaitu kompetensi pedagogik, kompetensi kepribadian, kompetensi sosial, dan kompetensi profesional juga merupakan bagian dari butir standar penilaian sumber daya manusia yang terdapat pada item BAN PT, standar 4.

\section{Sistem pembelajaran}

Pendekatan sistem pembelajaran pada pendidikan vokasi lebih mengarah kepada: pembelajaran yang berfokus pada pengembangan atribut-atribut keterampilan (atribute-focused), pembelajaran yang berpusat pada peserta didik (learner-centered); pembelajaran yang berpusat pada pekerjaan (work-centered) yang diadop dari 
[7], ternyata pada penelitian ini terbukti valid dan reliabel dalam mengukur variabel sistem pembelajaran pada pendidikan vokasi. Makna dari sistem pembelajaran yang dijabarkan pada questionnaire pada penelitian ini disesuaikan dengan prinsip, strategi dan filosofi pendidikan vokasi dan sejalan dengan standar BAN PT: sistem pembelajaran dibangun berdasarkan perencanaan yang relevan dengan tujuan, ranah belajar dan hierarkinya. Pembelajaran dilaksanakan menggunakan berbagai strategi dan teknik yang menantang, mendorong mahasiswa untuk berpikir kritis bereksplorasi, berkreasi dan bereksperimen dengan memanfaatkan aneka sumber.Pelaksanaan pembelajaran memiliki mekanisme untuk memonitor, mengkaji, dan memperbaiki secara periodik kegiatan perkuliahan (kehadiran dosen dan mahasiswa), penyusunan materi perkuliahan, serta penilaian hasil belajar.

Proses pembelajaran

Variabel laten proses pembelajaran dengan indikator: mutu data dan informasi; mutu pembelajaran; mutu kurikulum; dan mutu sumber daya, dari hasil penelitian ini terbukti memiliki validitas dan reliabilitas yang baik dalam merefleksikan kemampuan mengukur variabel laten proses pembelajaran, berdasarkan hasil uji validitas dan reliabilitas. Keempat indikator tersebut disimpulkan valid dan reliabel dalam mengukur faktor atau variabel proses pembelajaran pada pendidikan vokasi. Hal tersebut sesuai dengan yang direkomendasikan dari hasil penelitian yang dilakukan [21].

Produktivitas pendidikan vokasi

Konstruk produktivitas pendidikan diadaptasi dari [24] dengan mengajukan beberapa questionnaire. Indikator produktivitas pendidikan vokasi meliputi: mutu lulusan; mutu manajemen; efisiensi internal;efisiensi eksternal; dan penghasilan. Kelima indikator tersebut adalah valid dan reliabel dalam mengukur/mereleksikan faktor produktivitas pendidikan vokasidari hasil analisis data pada penelitian ini.

\section{KESIMPULAN}

Dari hasil penelitian dan pembahasan sebelumnya dapat disimpulkan sebagai berikut:

Indikator dan faktor determinan yang berperan terhadapproduktivitas pendidikan vokasi terbukti valid dan reliabel adalah faktor: (1) kepemimpinan pengelola dengan indikator: (a) idealized influence/karismatik, (b) inspirational motivation, (c) intelectual stimulation, (d) individualized consideration; (2) suasana akademik mempunyai tiga indikator, yaitu: (a) lingkungan fisik, (b) lingkungan akademik, (c) lingkungan belajar;(3) Learning System mempunyai tiga indikator, yaitu learner-centered; work-centered dan focusedoriented; (4) kompetensi dosen mempunyai empat indikator: (a) kompetensi pedagogi, (b) kompetensi profesional, (c) kompetensi kepribadian, dan (d) kompetensi sosial; (5) process pembelajaran mempunyai empat indikator, yaitu: (a) mutu data informasi; (b) mutu pembelajaran; (c) mutu kurikulum (d) mutu sumber daya; (6) poduktivitas pendidikan vokasi memiliki lima indikator, yaitu: (a) mutu lulusan; (b) mutu manajemen; (b) efisiensi internal; (d) efisiensi eksternal, dan (e) penghasilan.

Model Pengukuran faktor dan indikator yang berperan terhadap produktivitas pendidikan vokasi yang valid dan reliabel ditampilkan pada Gambar 1 (standard solution) dan Gambar 2 (T-value) dengannotasi sebagai berikut:

Manlead $=$ kepemimpinan pengelola; Atmosac $=$ budaya akademik; Lectcomp = kompetensi dosen; Teachsys $=$ sistem pembelajaran; Process $=$ proses pembelajaran; Product $=$ produktivitas pendidikan vokasi. Indikator sebagai berikut: $\mathrm{X} 1=$ idealized influence; $\mathrm{X} 2$ = inspirational motivation; $\mathrm{X} 3=$ Intelectual Stimulation; $\mathrm{X} 4=$ Individualized consideration; $\mathrm{Y} 1=$ lingkungan fisik; $\mathrm{Y} 2=$ lingkungan belajar; $\mathrm{Y} 3$ = lingkungan akademik; $\mathrm{Y} 4$ $=$ kompetensi pedagogik; $\mathrm{Y} 5=$ kompetensi profesional; $\mathrm{Y} 6=$ kompetensi kepribadian; $\mathrm{Y} 7=$ kompetensi sosial; Y8 = learner-focused; Y9 = worker-focused; $\mathrm{Y} 10=$ attribut-oriented; $\mathrm{Y} 11=$ mutu data dan informasi; Y12 = mutu pembelajaran; $\mathrm{Y} 13=$ mutu kurikulum; $\mathrm{Y} 14=$ mutu sumber daya; Y15 = mutu lulusan; Y16 = mutu manajemen; $\mathrm{Y} 17=$ efisiensi internal; $\mathrm{Y} 18=$ eisiensi eksternal; Y19 = penghasilan.

\section{DAfTAR PUSTAKa}

[1] Alan, Thomas, J.,1995, The Productin School: A System Analysis Approach to Education administration, Chichago University

[2] Bagozzi R.P.H. Baumgartener and Yi (1992). State versus action orientation and the Teory of reasoned action. Journal of consumer research.18.505-518.

[3] Boateng, C. (2012). Leadership and effectiveness of principals of vocational technical institution in Ghana. American 
International Journal of Contemporary, 2 (3), 128-134.

[4] Bentler,P.M. and D.G. Week (199) Signiicant Test and Goodness o Fit in analysis of covariance structures psylogical buletin. 88 . 588-606.

[5] Cai, Li \& Wang (2009). A discussion on integration of higher vocational collages'culture and enterprise culture. Journal of Jincheng Institute of Technology, 2 (1) 23 30.

[6] Chappell, C. (2013). Changing Pedagogy: Contemporary vocational learning. Research Working Paper 03-12. The Australian Centre for Organizational, Vocational and Adult Learning (OVAL). Sydney: University of Technology.

[7] Doll, W.,J.,Xia, W. \&Torkzadeh. (1994). Confirmatory factor analysis of the end usercomputing satisfaction instrument. MISQuarterly. December, 453-461. Bandung, Yayasan Amal Keluarga.

[8] Fornel, C.\&Larcker, D.F. (1981). Evaluating structural equation models with unobserved variables and measuring errors. Journal of Marketing Research, 18,39-50.London: Prentice-Hall International.

[9] Hashim, J., Mohamad, B., Abidin, B. et.al. (2013). Leadership in technical and vocational education. Journal of Technical EducatiTraining, 2 (1), 49- 66.

[10] Hair, J.F.,Anderson,R.E., Tatham, R.,et. al. (1998). Multivariate data analysis. 5th edition. London: Prentice-Hall International.

[11] Hazliza, N. Azlin, N., Azzarina, N. et. al. (2015). Leadership style head of Politechnic department and regard with to work culture. Journal of Education and Practice, 6 (15), 2330.

[12] Igbaria, M.,N., Zinatelli, P., Cragg et.al. (1997). Personal computing acceptable factors in small firms: A Structural equation model. MIS Quarterly. September, 279-299.

[13] Indrajid R.E. dan Djokopranoto, R., 2006, Manajemen Perguruan Tinggi Modern, Andi Offset, Yogyakarta.

[14] Indrasari, M.,Newcombe, P. Eliyana, A. et.al. (2015). The influence of academic climate and individual creativity on lecturer competence in private university at Surabaya Indonesia. International Journal of Business and Management, 10 (8), 127-133.

[15] Jöreskog, K. G. \&Sörbom, D. (1996). Lisrel 8: User's reference guide. Chicago.

[16] Krisnaveni, R., \& Anita, J. (2007). Educator's professional characteristics. Quality Assurance in Education, 15 (2), 149-161.

[17] Martono, T, Kepemimpinan kepala sekolah,kinerja guru, budaya akademik sekolah pengaruhnya terhadap produktivitas, http://pustaka.uns.ac.id/?menu=news\&0ption

[18] Rigdon,E.E. \& Fergusson C.E. (1991). The performance of the polychoric correlation coefficient and selected fitting function in factor analysis with ordinal Data. Journal of Marketing Research. 8 November, 491-497.

[19] Robbins, S.P., 2016, Prilaku Organisasi: Konsep Kontroversi, Aplikasi, Ed. Indonesia, Jakarta, PT. Prenhallino.

[20] Tableman, 2014, School Climate and Learning http://outreach.msu.edu/bpbriefs/issues/brief

[21] Walter, R.A., \& Grey, K. C. (2002). Preparing, licencing and certifying Post secondary career and technical educators Journal of Vocational Education Research, 2, 27-35.

[22] Twomey, S. M.(2002). The virtual teacher training centre a one year program to transform subject- matter experts into licensed career and technical education teacher. http://www.nccte.org/publications

[23] Yukl, G. (2006). Leadership in organizational (sixth ed). New Jersey: Pearson Prentice Hall.

[24]Zheng, L. (2014). Validation of a learning environtment instrument in tertiary foreign languagre classrooms in China, Review in Psychology Research, 3 (3), 27-36.

\section{BiodataPenulis}

Mulianti, lahir di Jambi, 1 Januari 1964. Sarjana Teknik Kimia dari Universitas Sriwijaya Palembang, lulus 1990. Tahun 1999 memperoleh gelar Magister Teknik Kimia pada Jurusan Teknik Kimia Universitas Gadjah Mada, Yogyakarta, Tahun 2016 memperoleh gelar Doktor Program PTK Universitas Negeri Yogyakarta. Peneliti pada Badan Tenaga Atom Nasional, Serpong, 1990 sampai 1992, peneliti pada Balai Litbang Industri Padang dari 1992 sampai 2008. Staf pengajar pada Jurusan Teknik Mesin FT UNP sejak tahun 2008sekarang. 
